rough knowledge of what is useful and practical. Under any circumstances, I am glad to think that the practical element in physiology is to be more cultivated.

In the case of practical surgery, attention to which is now specially enforced under the new rules, we must all admit that the change is most excellent. But the question has been raised, whether it is necessary that the practical sur. gery course should extend over six months-whether all that is embraced under this head might not be better studied in a three months' summer course. As operations on the dead body must form one element of the course, the difficulty of procuring a sufficient number of subjects will create perhaps a formidable impediment to its being carried on in the winter.

There is another point which must be considered, and on which it would be well could the schools come to a general agreement. It is true that many of the subjects which the new regulations render compulsory have been tanght in most of the schools in supplementary classes. For the most part these have been added on without the requirement of extra fees from the students who lenefit by them. The necessary expenses under the new rules must be increased. Should there not be a corresponding increase in the fees? You may say that this, at least, is no question of improvement of education; but I have no doubt that if the emoluments of teachers are reduced to a minimum, and their work is increased to a maximum, teaching will be carried on in an unsatisfactory manner.

Such, amongst others, are the questions which will more than occupy our time to-night.

Whatever may be our view as to the application of the new regulations, we cannot but be glad that they all tend to enforce practical teaching, and are so far in advance of the prevalent competitive examination system, which is, I believe, producing great injury to the minds of the rising generation. There is no doubt that the primary object of the teacher is to instil into the minds of the students as much knowledge as he can, and the new rules put fresh means and appliances into his hands. But it has always appeared to me that there is one, and that perhaps the main. branch of education which is in danger of being sacrificed in this attempt to instruct, and that is, teaching a student the uses and powers of his own mind. At the ordinary school he should be taught how to learn; at the special college he should be taught how to think and to reason. Our endeavour should be to induce him to try as far as possible to work out questions for himself, rather than to explain everything to him. One problem worked out by independent thought would be more useful to him than twenty of which he had learned the demonstration by kook. By such a process his mind will be rendered both more able and more willing to receive new truths and new ideas. Of course any information given to an intelligent being will fructify; but while a truth imparted will yield a twofold harvest, a truth educed will yield a hundredfold. The opportunity for this mental training is now placed more within the reach of the teacher, and it will be for us to utilise it. The task may be somewhat irksome, but it will always be beneficial. If well carried out in the practical courses, the clinical teaching will be far more interesting to the teacher, and far more useful to the student; and it is, after all, towards clinical teachino that our main endeavours must tend in the education of future practitioners.

I have said that we may congratulate ourselres on the establishment of the new regulations of the College of Surgeons; and $I$ cannot help thinking that, whether admitted or not, the strong and nnanimous opinion of so large a body of teachers as is enrolled in this Association has had some share in leading the College to frame them. It must have had the effect at least of satisfying the Council of the College that the rules would be cordially received and conscientiously acted upon by the teachers. And if this be so, have we not an answer to those who ask of what use is the Association? There is a doubt, perhaps, on the minds of some few who are of us, and work with us. For it is said that we do not represent the London schools. It is true, and it is a subject of regret; regret for our own sakes, as we are deprived of the advantage of gathering the opinions of men of experience,-regret for their salses who are not of us, inasmuch as they lose an opportunity of advancing an object of common interest to them and to us, of learning the opinions of men of equal experience with themselves on subjects which must engage their minds as deeply as they do our own. Though we may regret that any should hold aloof from us, yet I do not see that our position is materially weakened thereby, or our usefulness diminished. We are not, and we do not aspire to be, a legislative body. We do not seek to enforce laws even on schools affiliated to us. Our function is consultative, and our end is gained if we can obtain a concurrence of opinion on unsettled points on the part of so large a majority of the schools and teachers as belongs to our Association.

And our Association has produced another beneficial effect. Those who, like myself, have had experience in former years of the difficulty of obtaining anything like cohesion for any purpose amongst the London schools must be struck with the inclination displayed amongst us to merge individual interests in common benefit. Our rivalries may remain; but the frankness with which the various systems and opinions are explained and discussed shows that it is no mean or jealous rivalry which actuates us. For one, I may express $m y$ hope that the Association will continue, and will be a permanent benefit to what we may call the great metropolitan school.

I have intentionally condensed the thoughts which have passed through my mind within the narrowest possible limits. Our time for discussion is short. Inexorable custom has obliged me to occupy some part of it in expressing my own views; but in allowing as much as possible for the full consideration of the subjects which will be brought before you, you will agree with me in thinling that $I$ have best discharged my duties as your president.

\section{AN IMPROVED METHOD OF DIVIDING THE PEDICLE IN OVARIOTOMY.}

\section{BT GEORGE H. B. MACLEOD, M.D., F.R.S.E.}

REGIUS PROFESSOR OF SURGERY IY THE UNITERSITY OF GLASGOW; SCRGEON TO AND XECTCRER ON CLTYTCAL SLRGERT, ROYAL IN FIRMAMY; AND SCRGEON TO TIE LOCK MOSPITAL.

THE only step in the operation of ovariotomy to which the writer wishes at present to refer is the mode of dividing the pedicle, certainly not the least important or the least anzions which the surgeon has to consider.

Whatever method the operator employs to separate the ovarian tumour from its connexion with the uterus, he must desire-

1st. To arrest bleeding effectually and permanently.

2nd. To injure as little as can be the stump which remains.

3rd. To separate the growth and treat the remnant of the pedicle in such a way as to occasion least chance of peritonitis.

4th. To return no dead tissue, or structures likely to decompose (and be a source of septic poisoning), within the abdominal cavity.

5th. To displace the uterus and its appendages as little as need be from their normal position.

6th and lastly. 'Io close the abdominal cavity as quickly and as completely as possible.

It will in no small measure depend on how these ends are fulfilled what risk is run of hæmorrbage, peritonitis, and shock-the three great sources of mortality after ovariotomy.

The different plans in use of securing the pedicle may be thus summarised:-

1. Tying it in one, two, or more portions with whipcord or silk, catgut or wire, - the pedicle being divided a short distance on the distal side of the constriction. The stump is either fixed in the wound; or (when any of the agents mentioned are used except wire) the ligatures are cut short and returned with the stump into the abdomen; or, being uncut, are fixed in the lowor part of the wound, while the stump is dropped as before.

2. The pedicle is strongly constricted by a clamp, the growth cut away, and the stump fixed in the wound.

3. The division of the pedicle and the closure of its vessels may be achieved by the actual cautery, the stump being afterwards returned, or retained in the wound. 
4. The peritoneal covering of the pedicle being first incised, and then the pedicle, after which each separate vessel is taken up and tied, and the stump restored into the abdomen or fixed in the wound.

5. The écraseur has been employed to separate the ovarian tumour.

6. The pedicle having been transfixed by a strong ligature, and a long pin being passed through it and both lips of the wound, the ligature has been firmly twisted round the pin.

A consideration of the whole circumstances of the operation must impress the surgeon with the extreme desirableness of restoring the stump of the pedicle at once into the abdomen, if that can be accomplished without greater risk than attends its fixture in the wound. What has hitherto prevented this replacement being carried out was the peril of bæmorrhage and the injurious effects of returning tissue tending to decompose-the direct result of the mode in which the pedicle had been severed.

When we ligature the pedicle (whatever agent we employ for the purpose) we necessarily kill a certain amount of tissue distal to the place of constriction, and to return this (and any portion, however limited, of the ligature) into the peritoneal cavity must be attended with manifest danger, though, happily, such danger does not always eventuate in catastrophe. If, again, we leave the ligatures long and drop the stump, we add for a time (often many days) to the risk of having decomposing tissue in the abdominal cavity the additional hazard of keeping that cavity open, and traversed by materials which cannot fail to imbibe septic elements, and serve as conductors of secretions into the depths of the pelvis.

If, again, by the clamp or other means we fix the stump in the wound we cannot quickly or effectually close the abdominal cavity, or ensure it against the entrance of decomposing secretions by the side of the pedicle; and, what is much worse, and in fact is well known to augment greatly the peril of the operation, the uterus is violently dragged from its place and twisted on itself. That the clamp is no complete safeguard against bleeding is amply testified by the records of ovariotomy, and that its use necessarily retards recovery may be conceded.

That the écraseur has failed effectually to command hremorrhage, and that it causes so great a mangling of the stump as to occasion subsequent fatal inflammation, is only what those who have used it most would anticipate.

The cautery has frequently failed as a hæmostatic agent in ovariotomy (the bleeding being sometimes early and occasionally late of appearing), and its action is so violent that much tissue is killed; and so, if the stump is returned, the objection made to the ligature cut short holds; if it is not restored, then the same difficulty which attends the use of the clamp presents itself.

Of the results obtained from the division of the pedicle and the separate deligation of its vessels, the writer knows very little, but from its rare employment in this country he supposes they could not have been promising. There would be the hazard of foreign bodies placed within the cavity, the greater risk of vessels subsequently bleeding which were not at first observed, and the occurrence of oozing which no ligatures can effectually command.

Regarding the pin and ligatures nothing need be said, as the same condemnation which applies to the ordinary modes of deligation applies to that method.

The plan which it is the object of this paper to submit to the profession seems to the author to obviate the ehief objections before advanced against the methods at present in use, and though he has as yet only had one opportunity of submitting it to the test of practice, still it was so strikingly successful in that instance that he is somewhat sanguine of its adaptability to the majority of cases. Short, thick pedicles may possibly not be amenable to the following plan, but experience can alone fully determine this.

The instrument here delineated (Fig. 1) is employed to grasp the pedicle firmly near its uterine end. The blades $(a)$ are narrow, and, being male and female, they take a very firm hold; their apposition being retained by fixing the quadrant $(b)$ with the screw. The cyst is next cut away by dividing with a knife the extreme distal end of the pedicle, and the stump is caught, by means of the forceps here shown (Fig. 2), at a short distance from the part grasped by the instrument already spoken of. The form of the

blades and the quadrant and screw enables this instrument also to take and keep a very firm hold. By slowly turning the forceps while the first instrument is kept at rest, the

FIG. 1.

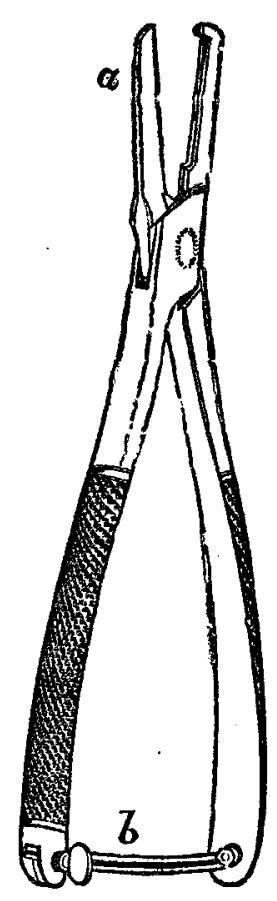

stump is twisted off close to the edge of the instrument by whirh it is held. Hardly any tissue remains external to the fixing blades, and the amount of injury done is most trivial. Possibly it would be better to incise the peritoneal covering of the pedicle before applying these instruments. The stump may now be returned with safety into the cavity of the abdomen, and the closure of the wound can be at once accomplished.

The case in which the writer employed this method was doubtless a very favourable one for such an experiment. Without entering into much detail, its leading features may be thus given :-

The patient was an unmarried healthy girl, nineteen years of age, who had suffered from an ovarian cyst of the right side for upwards of a year. The catamenia were scanty but regular* before admission into hospital. She had been once tapped, about two months before ovariotomy was performed. At the time of the operation she measured thirtynine inches in circumference at the level of the umbilicus. The uterus was central, movable, and of normal size. Fluctuation was marked and widespread. The abdominal parietes were unusually thick, and not apparently adherent to the cyst.

Ovariotomy was performed, in the presence of many medical men and students, on the 26th December. The chloroform was admirably managed by the house surgeon, Mr. Reid. No sickness followed. It is unnecessary to repeat the various steps of the operation. No bloodvessel was tied or twisted. There were no adhesions. The parent cyst was large, and enclosed many secondary cysts having various contents more or less glue-like. The whole weighed $21 \frac{1}{2} 1 \mathrm{~b}$., not calculating much fluid imbibed by clothes, \&c. Not a drop escaped into the abdomen. The pedicle was of medium length, and was treated as before described. More time was taken up in the twisting than was probably necessary, from the desire not to rupture the pedicle prematurely; yet it is doubtless requisite for security that the torsion should be slowly performed. Not a drop of blood escaped, and the stump was replaced into the abdomen, and that cavity closed in the usual way, but not so thoroughly as in future cases would be accomplished, simply because of the fear that, after reaction was established, it might have to be reopened to command bleeding.

Not a bad symptom followed. The day after the operation a too tight strip of plaster caused the patient some pain, which was easily allayed by removing the cause, and she had

* A case operated on by the writer a few months ago, in which, with large eysts in both ovaries, the catamenia hid remained quite regular up to. the time of the operation, tends to diminish the value of such an occurrence in a diagnostio point of view. 
also, as is usual, some annoyance from flatulence; but, beyond this, she so rapidly recovered that, if it had not been for the dread of running unnecessary risk, she might have been sitting up in a week. She was allowed, however, to sit up on the eleventh day; and was altogether beyond restriction as to food \&c. in a fortnight. 'The exceeding thickness of the abdominal parietes and the paucity of sutures employed caused the superficial portion of the wound to remain open longer than would otherwise occur. The exceedingly little general disturbance which followed, together with the perfect result, was not more gratifying than remarkable to all who watched the progress of the case. She was quite recovered about the time the clamp is found to separate in most cases.

The perfect arrest of all bleeding by the torsion was very striking, and, as it occurred in a strong healthy patient, it was a fair test of its power. Hardly a trace of injured tissue was left; immediate replacement was accomplished; the uterus and its appendages were restored to their normal position; and the abdominal cavity was effectually, quickly, and completely closed. In short, every operative requirement as regards the pedicle was fulfilled.

It is a question for further observation how far the simple grasp of the first instrument, if continued for a short time, might suffice to close the vessels of the pedicle without the torsion. If that succeeded, it could be applied below the peritoneal covering of the stump, and all tissue beyond it cut cleanly away.

In conclusion it may be stated that the idea carried out in the use of these instruments arose from seeing the apparatus employed by veterinary surgeons for castrating the horse lying in the shop of our most able hospital mechanist, Mr. Hilliard, and the strong conviction he expressed that some sach appliance would be found an efficient hæmostatic agent in ovariotomy. The instruments before delineated were made by him for the author, as also a light and most ingenious clamp (Fig. 3,e), which is firmly closed by means of forceps $(g)$, and quickly disengaged from its blades $(f)$ when required, as the jaws of the forceps only lightly catch in the indentations or grooves on the sides of the clamp.

FIG. 3.

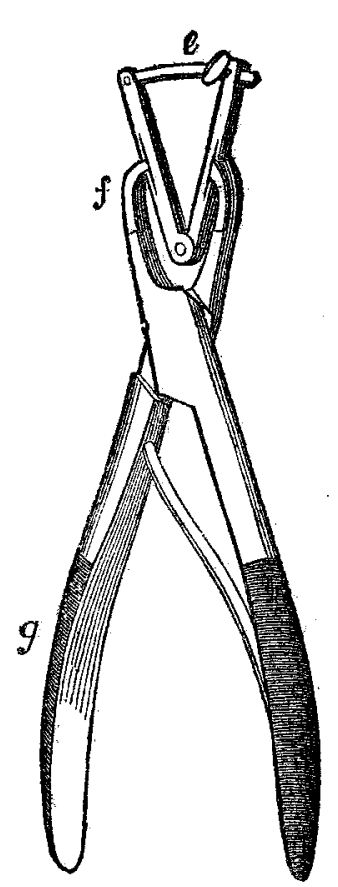

It may also be added that Nélaton's forceps for grasping the sac (Fig. 4) have proved in the writer's hands most useful. The flat broad blades $(h)$ with teeth take a good hold, and yet do not tear, and the catch $(i)$ between tho handles keep them solidly in place.

If ovariotomy were an operation of every-day occurrence, the writer would not have published these remarks till he had tested his suggestion by a number of cases; but as, at best, weeks or months may pass before he can further employ the method described, and the matter is an important one, he judged it best to submit the plan at once to the profession.

Woodside-crescent, Glasgow, January, 1871.

\section{THE CAUSATION OF SCARLATINA.*}

\section{Bx ALFRED CARPENT'ER, M.D. LOND.}

I PRopose to consider scarlatina as one of a serics of diseases which are epidemic at times, produced by a combined force which results from the effect of matter acting upon blood more or less impure.

The equation $x, y, z=$ epidemic disease, is the first proposition. It is proposed to consider $x, y$ as centric members of the equation-centric, that is, so far as the body is concerned; and that $z$ is excentric or obtained from without. It is proposed to consider that $x, y, z$ may equal typhoid, or typhus, or cholera, or scarlatina according to the particular quality or power of the member $z$. In the equation, $x$ is assumed to be the constant quantity of used-up materialthe débris which naturally results from the act of living, ever present in every person, and always being removed in those who are healthy by various excretory organs. If all organs were perfectly healthy, $x$ would be constant in quantity; but as this is not often the case, $y$ puts in an appearance, and represents the change which results from the effect of disorazer upon one or more organs: it is a variable and unknown quantity, and a necessary result of imperfect excretory function. $z$ is a something not belonging to the human economy. It is introduced from without; and, by its effect upon $x, y$, sets up an action represented as $x, y, z$, which equals epidemic disease. Now, upon the quality of $z$ depends the character of the disease set up.

The proposition, therefore, is that $x$ being a constant quantity, $y$ will vary according to the circumstances in which a community is placed as to its moral and its sanitary state, and its obedience to sanitary laws. If by their neglect the conditions requisite for the increase of $y$ have arisen, a state of system is produced favourable for the production of epidemics. If $z$ is then imported, the epidemic will be more or less fatal according to the value of the quantity $y$ and the concentrated state of the excentric factor $z$. If sanitary laws have been fairly observed, then the effect of $z$, whenever imported, will be a minimum, and, in the case of scarlatina, will produce the mildest possible form of epidemic.

The writer proposes to show what is the nature of this factor $z$ upon which he assumes that scarlatina depends.

Hitherto it has been found that scarlatina is less amenable to prophylactic measures than some other enthetic diseases. It does not depart from those places in which the usual sanitary operations have been carried out, such as the supply of pure water, the abolition of cesspools, and the construction of properly designed sewers. It has therefore an element in its total somewhat distinct from typhus and typhoid. It has a relationship to them, inasmuch as it appears to make itself felt at times more fatally in those very places from which the two former have been banished. As it appears that typhoid is often most prevalent in those towns from which typhus has been routed, so scarlatina is more constant in those districts from which typhoid has been more or less perfectly removed. Just now it is much more general and more fatal than typhus, though closely allied to it in some of its prominent symptoms.

There are two opinions current regarding the origin of scarlatina in a given district from which it had been previously absent. One is that the primary cause of the outbreak is infection from some preceding case. It is assumed to be, like small-pox, unable to arise without its advent being preceded by some atom or germ of matter developed in a former case of the same disease, and carried in some way to its present habitat; or, if produced there, that the atom must have lain dormant until kindled into activity by some predisposing or exciting causes not always existing. Those who hold this opinion consider that the disease will be only combated by disinfection and complete isolation; they would stamp it out like small-pox or rinderpest; and some think that a measure yet to be discovered, allied to vaccination, will be a very effectual preventive agent. The other opinion, and the one to which I hold, is, that though highly infectious when actually present, and when brought

* Read at the meeting of the Medical Society of Loudon held on the 16 th of January, 1871 . 